\title{
Reseña: Virginia Vidal, Letradura de la Rara. Una historia de heroínas anónimas. Ceibo Ediciones, 2013.
}

Poco es lo que se conoce de las mujeres que vivieron en el Chile de la primera mitad del siglo XX. De los inicios del movimiento feminista obrero que desarrolla y profundiza sus análisis sobre la insubordinación y emancipación femenina en defensa de la educación y organización para mujeres. De ahí la importancia de esta novela, que retrata la vida de tres generaciones de mujeres obreras a comienzos del siglo pasado.

Amarga es obrera, su hija Mercedes de niña empieza a trabajar en una fábrica y venciendo todo tipo de desgracias logra forjarse como dirigente. Madre e hija encarnan la dualidad de la mujer como signo de la doble explotación capitalista: por clase y género. En ellas, también habita la desobediencia y el castigo.

Amarga, la abuela, se ocupará de abrir a los suyos una puerta al saber y el conocimiento, respecto de los bienes, imponiendo con disciplina y rigor la lectura de libros en sus hijos y nietos como condición básica para dejar de ser explotados.

Historias de la vida, no más, les contaba a sus hijos amita Marga. Nunca un cuento de hadas. No supieron de canciones de cuna, pero sí de poemas que sacaba de un libro gastado y guardado por ella como tesoro. (45) 
Cabe destacar la trágica figura de Yolita, joven compañera de Mercedes. Metáfora de la mujer pobre, explotada, bonita, que sufre un accidente en el trabajo, un corte en la cabeza en una máquina muy peligrosa. Símbolo del capital y figura máxima de castración, ella es el sacrificio de lo femenino.

Atravesamos los tiempos de Luis Emilio Recabarren. El inicio de los movimientos políticos y sociales, las mujeres salen a buscar trabajo en las fábricas. Reales o de ficción, los personajes, habitan el Chile explotado, para dar cuenta de sucesos que anticiparán las formas contemporáneas de desigualdad, injusticia y explotación.

Avistamos el auge de la producción salitrera, las huelgas contra las miserables condiciones en que los obreros trabajan que culmina en 1907, bajo el gobierno de Pedro Montt con la gran masacre de la Escuela Santa María de Iquique, que buscó castigar al movimiento obrero y la efervescencia de los tiempos de un modo brutal. Miles de personas: hombres, mujeres y niños, mueren acribillados. El poder amenazado, actúa, reprime, asesina. Una historia de violencias y desenlaces trágicos, de silencios y borraduras, que se repetirá hasta hoy.

Así era la vividura. Sólo los entierros sacaban al aire la palabra indignada. Crecían los rumores sobre muchos otros obreros presos y torturados había en el país. No de todos se sabía; aun de algunos llegaban las noticias cuando ya los habían matado. O se habían suicidado. "el suicidio no es sino otra forma del asesinato. (84)

José Domingo Gómez Rojas, poeta chileno, uno de los gestores de la agitación callejera, es apresado y termina suicidándose en la casa de Orates.

Con la muerte, José Domingo conseguiría el cumplimiento de uno de sus sueños: la Huelga General. Las industrias se paralizaron y todos los trabajadores salieron a la calle. (84)

En 1935, Elena Caffarena convoca a las mujeres históricamente relegadas al margen del poder y la política a movilizar sus roles circunscritos a la casa, el 
marido y los hijos para despertarlas de su estado de postergación. Otra referencia clave, es la novela María Nadie, de Marta Brunet, publicada en el '57, que describe a la mujer moderna, soltera, que se traslada de pueblo para trabajar en el servicio público. María López, representa el desorden de las normativas de la época y el riesgo de su posible disolución. Ella es expulsada del espacio provinciano, pero con un empleo y salario pagado por el Estado, consigue un lugar en el mundo.

Con Letradura de la Rara, Virginia Vidal desarrolla un escenario poco explorado por los textos escritos por mujeres, y lo hace desde el cuerpo de las trabajadoras y obreras vulnerables y vulneradas que habitan la urbe recreando sus hablas desde la frágil humanidad de los oprimidos. Sus protagonistas, son sobrevivientes que trabajan en fábricas o circulan al interior de los conventillos.

Este conventillo es el espejo podrido a los pies de su palacete: el mismo zaguán, los mismos salones laterales; el mismo patio rodeado de unos catorce claustros, tres excusados y un par de baños: uno de los hormigueros para las hormigas dedicadas a llenar el granero. (12)

La marginalidad cruza sus cuerpos, no desde la derrota o el drama, sino desde la vida misma, entre saberes y poderes en lucha contra un escenario hostil. Sus experiencias encarnan el orgullo y la dignidad de la clase obrera, de sus mujeres rebeldes, valientes, fuertes que a pesar de atravesar todo tipo de penurias, no se someten y luchan, viven y se divierten, aceptando con dignidad las condiciones precarias. Generaciones de mujeres con sus diferencias, las nuevas crianzas, ellas harán lo que sea con el fin de aportar a los anhelos de todos, buscando mejorar las vidas de las nuevas generaciones. A veces solidarias, otras crueles, entre amores, desconfianzas o envidias la vida se moviliza.

Se advierte el sarcasmo, la rebeldía en los diálogos de Amarga y Doña Joaquina, su patrona.

—Ay, Marga, ¿otro descuido?

— ¿Conque los míos son "descuidos" y los suyos, hijos? Responde. 
—No se me alce, que la estoy necesitando... Para que vea, yo seré la madrina de su guagua. (13)

Este texto tiene una notable construcción de diálogos que permiten seguir la lectura con fluidez, capturando en interés de lectura. Su capacidad de cronista le permite configurar ambientes cargados de detalles, texturas y atmósferas que enriquecen el relato.

- Hasta ahí, no más, llegáramos. Nunca le anduve bailando el agua a ningún patrón. Si me echara, saldría perdiendo: jamás se ha quejado nadie de mi trabajo. Recuerde, Fidelina, los apocados no tienen perdón de Dios.

- iBien bueno! Estamos a merced de una rota alzada y de una china caliente... Miren que voy a someterme a sus reverendas ganas...

- Prefiero llevar mi bolsa, no voy a salir a la calle con este capacho igual al de Fray Andresito, dice Mercedes.

-Vean: tiene sus mañas de pisiútica, ¿ah? ¿Y esta bolsa tan linda? Responde la patrona.

—Pensándolo bien, doña Joaquina, los antepasados suyos eran los verdaderos anarquistas.

- Usted, Marga, es muy contestadora y se me está poniendo demasiado resuelta, tanta guapeza no me está gustando. Debe aprender a ser más moderada y comportada...

Hoy, en el siglo XXI, Virginia Vidal escribe desde la biografía y lo hace con puño firme, con obstinación, porque sabe, conoce. Su lengua es portadora de la historia de mujeres fuertes en un texto que consigue momentos poderosos.

No me vengáis con el cuento de perdón y amor. Si no nos atrevemos a odiar, jamás vamos a saber amar. La miseria tiene padres. ¿Quién va a responder por los tontos de hambre, tos y sabañones? ¿Por los atados de mocos, pidulles y tisis? ¿Han pensado que la explotación convierte al humano en algo más rebajado que un animal? No hay peor humillación en este mundo donde nos rotean a cada paso" (67). 
Sin duda, este texto, escrito con palabras poco comunes, antiguas, algunas muy raras, exigió una gran demanda para la autora, pero con esta obra literaria, consigue dar con un imaginario de época y un registro de lo real.

A medida que avanzamos, la lectura se vuelve más apasionante. Recorremos las fábricas textiles donde se explota la mano de obra barata de las mujeres. Nos asomamos al interior del conventillo. Entre pactos, alianzas o insultos, se comparte lo mínimo en piezas donde se pelean los pequeños territorios con la familia, los vecinos, en una indigna promiscuidad.

¿Qué amor puede haber en un conventillo donde se entra a un laberinto de humo y hediondez? Es una blasfemia hablar de amor donde violan hasta a las inválidas. (68).

Reconocemos lugares y oficios tradicionales, desplazados hoy por tecnologías y máquinas.

Parecía endemoniada, las manos conducían los cortes bajo la aguja desbocada, sus talones subían y bajaban, aferrados los pies en el pedal; todo su cuerpo se recogía, aparentemente inmóvil, generando fuerza para acelerar la máquina. Ella era el motor. (168)

Entre recetas para las enfermedades, chiches, piojos o sabañones, afloran las diferencias y tensiones de la clase, la pobreza, el ascenso, la siutiquería. Supersticiones y secretos caseros para la falta de agua, higiene y comida. Son instantes de luchas, sueños y aprendizajes en que alegrías y anécdotas mínimas nos conectan con los pequeños placeres, una comida especial, un postre, algún detalle en el encaje de un vestido o en un par de zapatos.

Letradura de la Rara opera como registro histórico desde una épica, una memoria colectiva que recoge las experiencias de la clase obrera devastada por el capital, un pueblo oprimido pero siempre resistente. Su palabra se extiende para insuflar en los personajes la vida que imaginó, creando una realidad difusa que, a ratos, se desvanece. 
$\mathrm{Su}$ escritura se mueve entre fronteras, desde una épica que cruza lo biográfico, el texto circula entre los géneros literarios, prosa, crónica, relato periodístico fundiéndose en un proyecto ambicioso, como si buscara abarcar lo que se acumula a lo largo de una vida.

Con esta novela, Virginia Vidal se instala en la tradición de la novela social chilena que dio origen a las narrativas de Nicomedes Guzmán y de Volodia Teitelboim, donde asignan a la literatura un rol de transformación social, y de arma ideológica de lucha.

Los mismos conventillos que la autora incorpora en su obra aparecen también en las novelas de Guzmán, en La sangre y la esperanza y en Los hombres oscuros, o en Hijuna de Carlos Sepúlveda Leyton. Pero Vidal va más allá, para resolver una deuda que la generación del '38 tenía pendiente con las mujeres que no pasaban de ser adornos o detalles en el paisaje proletario.

Con puño implacable, Virginia Vidal se compromete y arriesga alzando su discurso al momento de señalar las injusticias y vejámenes. Sobrevivientes de la pobreza que nos tocó, por nacer en un lugar y no otro, contra los alineamientos de los cuerpos y las edificaciones simbólicas a las que fuimos consignadas las mujeres, finalmente se asume el papel protagónico que siempre hemos mantenido en la batalla por nuestras reivindicaciones y desde una escritura no exenta de sarcasmo, humor y ternura, la autora construye un espacio en la narrativa de mujeres que, con la fuerza de la vida, la historia, y la experiencia, se escribe desde abajo. Allí se concentra su propuesta, su valor y su riqueza.

No somos sencillas sino armadas contra toda desilusión. Dice la autora.

(oc) $\mathbf{E Y}$ ULIS D-Sorle
New articles in this journal are licensed under a Creative Commons Attribution 4.0 United States License.

This site is published by the University Library System, University of Pittsburgh as part of its D-Scribe Digital Publishing Program and is cosponsored by the University of Pittsburgh Press. 